\title{
The Who, Why, and When of Uber and other Ride-hailing Trips: An Examination of a Large Sample Household Travel Survey
}

\author{
[Published in Transportation Research Part A: Policy and Practice]
}

Mischa Young, Department of Geography \& Planning, University of Toronto.

Mischa.young@mail.utoronto.ca

Steven Farber, Department of Human Geography, University of Toronto Scarborough. steven.farber@utoronto.ca

\begin{abstract}
:
Convenience and low prices have enabled ride-hailing companies, such as Uber and Lyft, to position themselves amongst the most valuable companies within the transportation sector. They now account for the lion share of activities in the platform economy and play an increasing role within our cities. Despite this, very little is known about the type of people that use them, nor the purpose and timing of trips. In addition to this, their effect on other modes, such as taxis and public transit, remains, for the most part, widely unexplored. By comparing the socioeconomic and trip characteristics of ridehailing users to that of other mode users, we find ride-hailing to be a wealthy younger generation phenomenon. While our results show that ride-hailing is too minute and inconsequential to influence the ridership level of other more substantial modes of travel overall, when considering specific market segments, the rise of ride-hailing corresponds to a significant decrease in taxi ridership and a rise in active modes of travel. Moreover, due to the specific age, timing, and purpose of our subsample, we believe that ridehailing may effectively reduce drunk-driving, and are convinced that as this mode increases in importance in the future, it will have a much more pronounced effect on the level of ridership of other modes as well.
\end{abstract}

\section{Keywords:}

ride-hailing; ride-hailing; Uber; travel behaviour; demographics; survey analysis 


\section{Introduction:}

Following their introduction just under a decade ago, ride-hailing companies, such as Uber and Lyft, have rapidly positioned themselves among the most valuable companies within the transportation sector. Most remarkable of all, is that they have achieved this feat without owning the cars in their fleet or having to hire drivers as employees (Henao, 2017). Instead, their success has largely hinged on their insight and ability to take advantage of the widespread adoption of smartphones and their built-in GPS technology to compete with the taxi industry and provide real-time information about wait times as well as a simplified method of payment. It is now estimated that over 20 percent of American adults use ride-hailing (RS) services, and that Uber - the most valuable RH company, which recent estimates report to be valued over $\$ 62.5$ billion (Henao, 2017) accounts for more than two-thirds of all activity within the platform-based labour market (Harris and Krueger, 2015). Yet, despite their soaring market valuations and growing role within cities, very little is known about the type of people that use RH services, or the purpose and location of RH trips. In addition to this, their effect on other modes, such as taxis and public transit, remains, for the most part, widely unexplored. Using survey data from the City of Toronto, this paper wishes to address these aforementioned questions by first comparing the socioeconomic and trip characteristics of $\mathrm{RH}$ users to that of other mode users, and by secondly using prior versions of the survey $(2011,2006,2001)$ to reveal whether RH services have had an effect on the ridership levels of other modes of travel. By providing a better understanding of the type of users and the repercussions RH services have had on other modes, this research aims to better inform transport planners and policy makers on how to properly regulate this innovative form of travel. 
In the following section we consider how, and to what extent, urban transportation systems have been disrupted by the arrival of RH services, and examine the, albeit limited, literature on RH and its implications on travel behaviour, mode shift and other aspects of urban transportation. The third section presents the 2016 Transportation Tomorrow Survey (TTS) and explains how it will be used to assess the issues at hand. We then focus on the socioeconomic characteristics of RH users and present findings on the purpose and timing of RH trips. These findings are accompanied by comparisons to previous TTS surveys to determine whether RH has impacted the ridership from other modes. We discuss these findings in the fifth section of this paper, focusing primarily on their implications for cities and the limitations of this study. A brief summary and concluding remarks comprises the final section of this paper.

\section{Literature review:}

Due to the novelty of $\mathrm{RH}$ services and the lack of data openness from its major companies, a paucity of literature on the implications of these services is to be expected. Nevertheless, of the literature that has focused on the disruptive nature of RH services, the majority has looked at the effects of Uber on the taxi industry.

Unlike taxis, RH companies often frame themselves as ridesharing services in order to avoid the safety, labour, and supply regulations that face the taxi industry (Kalanick and Hempel, 2013; Cohen and Shaheen, 2016). This, supporters claim, is necessary in order to achieve a "critical mass" of drivers and users, but is also perceived as unfair, as $\mathrm{RH}$ drivers, in contrast to more traditional ridesharing drivers (such as carpooling or vanpooling), can live off these earnings. Indeed, the number of taxis in a city is often limited by the number of medallions or vehicle-for-hire license plates that are 
issued. Regulations are used to determine fare prices and assure consumer safety, but may also raise the cost for consumers and drivers ${ }^{1}$ as they lead to a misallocation of resources and potentially insufficient supply to meet consumer demand. RH companies on the other hand, often operating under the less regulated rideshare classification, are not limited by medallions or licences plates, and drivers are able to adjust with respect to current demand (Cohen and Shaheen, 2016). This is the case in Toronto, where, despite passing a bylaw on March $31^{\text {st }}, 2016$, to level the playing field between the taxi and RH industries, the City agreed not to impose a limit on the number of vehicles affiliated with RH companies. On July $15^{\text {th }}, 2016$, a few months after passing this bylaw, the City then enacted the Municipal Code necessary to create a new legislative framework for private transportation companies (PTCs), and thereby legalized RH services. To ensure consumers safety and reduce the imbalance between the taxi and RH industries, the City also required RH drivers to acquire a new class of licence, entitled a PTC license, and to meet the same criminal background and driver screening requirements as for the taxi and limousine industries (Toronto, 2016b). This flexible labour supply, enabled by not having the same restrictions as taxis, was further enhanced by the fact that many RH companies practice surge pricing, which adjusts the cost of rides to match real-time demand and assures that a sufficient level of supply will always be available to meet consumer demand. Together, this flexible labour supply and use of novel technologies to facilitate driver-passenger matching and payments render RH a convenient and efficient substitute to taxis and an increasingly attractive travel option within cities (Hall and Krueger, 2018).

\footnotetext{
${ }^{1}$ The scarcity of taxi medallions in New York City eventually caused their value to rise to $\$ 1.32$ million in May 2013 (Barro, 2016).
} 
Still comparing RH services to the taxi industry, but focusing more specifically on user characteristics, Rayle et al. (2016) conduct an intercept survey by stopping RH customers on the street of San Francisco and found them to be much younger, more highly educated, and much less likely to own a car than taxi users. These findings were later corroborated by Clewlow and Mishra (2017), who, using a targeted email approach, compared RH passengers to the rest of the population in seven major American cities and also found RH users to be younger, more educated, and to have higher than average incomes. A noteworthy caveat acknowledged by the authors however, is that their use of a one-time travel survey may be insufficient to fully capture and understand the array of travel decisions impacted by the arrival of $\mathrm{RH}$ and that more longitudinal data was required (Clewlow and Mishra, 2017).

Another considerable body of literature on RH focuses on its potential to curtail the occurrence of drunk-driving and its many ensuing fatalities. Indeed, in a recent report published by Uber in collaboration with the Mothers Against Drunk-driving (MADD), driving under the influence of alcohol was found to have dropped considerably among drivers aged 30 or younger in all American cities that had allowed Uber to operate (MADD, 2015). Greenwood and Wattal (2015) also found the entry of UberX, Uber's most popular service, to be negatively correlated with the rate of motor vehicle homicides in California, but noted this relationship to subside once surge pricing was in effect. These findings were further substantiated by survey participants reporting, even when unprompted, that alcohol consumption was a major consideration in their decision to use RH services (Clewlow and Mishra; 2017, Murphy and Felgon, 2016). Nevertheless, when using actual traffic fatalities data, Brazil and Kirk (2016) found no significant 
reduction in drunk-driving fatalities in cities that had allowed $\mathrm{RH}$ services to operate. This they explained was most likely due to Uber's 450,000 drivers only representing a drop in the ocean in comparison to the 210 million licensed drivers in the US and the estimated 4.2 million adults who drive while impaired by alcohol in any given month. RS's alleged potential to reduce drunk-driving will be assessed in our study by measuring the number of users that exhibit travel patterns prone to alcohol consumption. More specifically, if RH does reduce the occurrence of drunk-driving, we expect to find a higher proportion of young users, evening and night trips, as well as many Other purpose trips, which includes entertainment, bars, and other alcohol-related activities.

Other authors have considered whether RH services actually reduced gross vehicle kilometers traveled (VKTs), as promoted by Uber and other prominent RH companies, or whether they instead lead to an increase in motorized travel. On the one hand, RH services may help eliminate wasteful driving such as the search for parking and in so doing reduce overall VKTs (Anderson, 2014). Yet on the other hand, RH drivers must first drive to get to the passenger's pick up location ${ }^{2}$, and because of this, will likely require more VKTs than what the passenger would have needed were he or she to have used a personal vehicle (Clewlow and Mishra, 2017; Schaller Consulting, 2017). Furthermore, when prompted, a considerable portion of passengers in San Francisco reported that, were it not for RH services, they would not have conducted the trip in the first place $(8 \%)$, or that they would have used a taxi $(39 \%)$, public transit $(33 \%)$, or walked/biked (10\%) instead (Rayle et al., 2016). Thus suggesting that about half of the VKT generated by RH can be considered as a net addition to total VKT in the region.

\footnotetext{
2 This is most often referred to as deadheading miles and has previously been estimated to represent as much as $20 \%$ to $50 \%$ of the trip itself (Cramer and Krueger, 2016).
} 
These results also indicate that RH may be a substitute for other modes than just taxis, and that it may in fact be taking users away from more sustainable modes such as public transit and active modes of travel. This has become one of the major criticisms of Uber and other RH companies, and has led some to categorize these services as being detrimental to a city's sustainable transportation objectives (Henao, 2017). Clewlow and Mishra (2017) for instance, measured the transport implications for major American cities following the arrival of Uber, and concluded that, all else being equal, $\mathrm{RH}$ services were responsible for a $6 \%$ reduction in transit usage. Silver and Fisher-Baum (2015), voiced a similar concern when noting that "If Uber is worth its $\$ 50$ billion valuation, it will have to do more than win over the market historically occupied by the taxi and limo industry - it will have to identify new types of customers." The growing fear that RH users are substituting away from transit and that overall $\mathrm{RH}$ services were detrimental to transit agencies was however refuted by Rayle et al. (2016) whom emphasized the gapfilling potential of RH services and their ability to provide access to car-free individuals living in areas where transit is not well served. Bialik et al. (2018) also recognized RS's gap-filling potential and supported this claim by showing that many of Uber's strongholds in New York City are located in areas that are poorly serviced by transit and where a transit trip to Midtown would be very time consuming. Moreover, Murphy and Felgon (2016) find RH and transit to be fairly complementary and to serve entirely different purposes. Only $21 \%$ of RH customers in their survey indicated using this mode of travel for commuting, whereas a much larger portion of participants attest using transit for this purpose. Furthermore, RH was found to be the most popular mode of travel in late evenings and at night - often the time of day when transit is less frequent - and was 
shown to be the least frequent mode choice during the morning and evening rush (Murphy and Felgon, 2016). Looking at this question from an economic perspective, Hall et al. (2017) established Uber to have a complementary effect on transit in cities with a low transit ridership prior to its arrival, and to have a substitution effect in cities with high transit ridership to begin with. This, they explain, was due to transit ridership being positively correlated to the level of transit services, and to Uber's ability to offer additional flexibility to transit riders in areas and times when transit supply was clearly insufficient. Moreover, transit riders in large cities tend to be wealthier, which increases the overlap between those who ride transit and those who can afford to take Uber, and leads to a more pronounced substitution effect. According to their logic, the City of Toronto should therefore experience a substitution effect as it boasts the third largest transit ridership in North America (Toronto, 2016a). Despite this ongoing debate, RH services remain expensive, especially in comparison to transit, and are therefore only available to those who can afford to pay for these services. Moreover, RH services rely on smartphone technology to request trips, which imposes yet another financial barrier and reduces even further the possibility of $\mathrm{RH}$ as a travel option for lower-income residents. This equity gap is of particular concern lately, as transit agencies are increasingly considering ways to integrate $\mathrm{RH}$ services into their operations (Cohen and Shaheen, 2016; Cane, 2017).

\subsection{Paper objectives}

This paper wishes to expand on previous research by using the most recent 2016 TTS, which for the very first time includes RH as one of its travel mode options. Using this novel travel mode inclusion, we first compare the socioeconomic and trip characteristics 
of RH users to that of other mode users to verify whether RH users are different and behave differently to the average population in Toronto. In addition to this, we seek to add empirical evidence to the debate on whether RH impacts the ridership level of other modes of travel by considering the timing and purpose of trips within the central Planning Districts of the City of Toronto. Finally, using our prior findings on the socioeconomic characteristics of $\mathrm{RH}$ users as well as the timing and purpose of $\mathrm{RH}$ trips, we investigate whether RH can efficiently serve to reduce the occurrence of drunk-driving. The analysis is further enhanced by comparing the mode share in the 2016 TTS to that of previous TTS cycles in order to provide insight as to whether the arrival of $\mathrm{RH}$ services have impacted the ridership level of other modes of travel.

\section{Methods:}

3.1. Study area and Survey:

This study takes place in the City of Toronto, which is the largest city in Canada and the fourth largest in North America, with a population of 2.7 million (Statistics Canada, 2016). While RH arrived in Toronto as early as 2012, the adoption and widespread use of these services only occurred in the second half of 2014, with the introduction of Uber's UberX service - as measured by the relative increase of Google searches for "Uber" in Ontario at that time. According to Kolanko and Galliger (2015), the rising popularity of RH services in Toronto is due to their convenience, and also to them being considerably less expensive than traditional taxi services. Indeed, even after reducing the taxi base fares by $\$ 1$ in 2015, Toronto's taxi rates remained among the most expensive in the world, and RH companies were thus able to systematically undercut these rates by up to $50 \%$ (Kolanko and Galliger, 2015). As a point of comparison, the $28 \mathrm{~km}$ ride from 
Toronto's downtown City Hall to Pearson Airport would cost $\$ 35-45$ by UberX (depending on surge pricing), $\$ 56.80$ by taxi, and as little as $\$ 12$ using Toronto's new UP Express transit line. Also worth noting is that taxi costs often require a customary $15 \%$ gratuity over the required fare. By contrast, tipping was not introduced as an option through Uber's RH platform until July 2017.

The data used for this study comes from the TTS, a cross-sectional household travel survey conducted in the Greater Golden Horseshoe Area in Southern Ontario once every five years since 1986 (Data Management Group, 2017). Despite the sheer size of the area covered by this survey, we only include respondents living within the six central Planning Districts of the City of Toronto. These PDs cover the entire downtown area of the City and represent over $50 \%$ of all RH trips while accounting for only $14.4 \%$ of the population and less than $1 \%$ of the overall size of the region's area (Statistics Canada, 2016; TTS, 2016). ${ }^{3}$ The number and density of RH trips in all other areas of the Golden Horseshoe was too low to include in our analyses. A map of the study area can be found in Figure 1.

\footnotetext{
${ }^{3}$ Our methodology only includes trips made by individuals living within the six central Planning Districts of the City of Toronto. It excludes all trips made by respondents living outside this area, even if their trips are made within these boundaries.
} 
Figure 1. Planning Districts in the City of Toronto (in grey are those used for this research)

Source: TTS (2016)

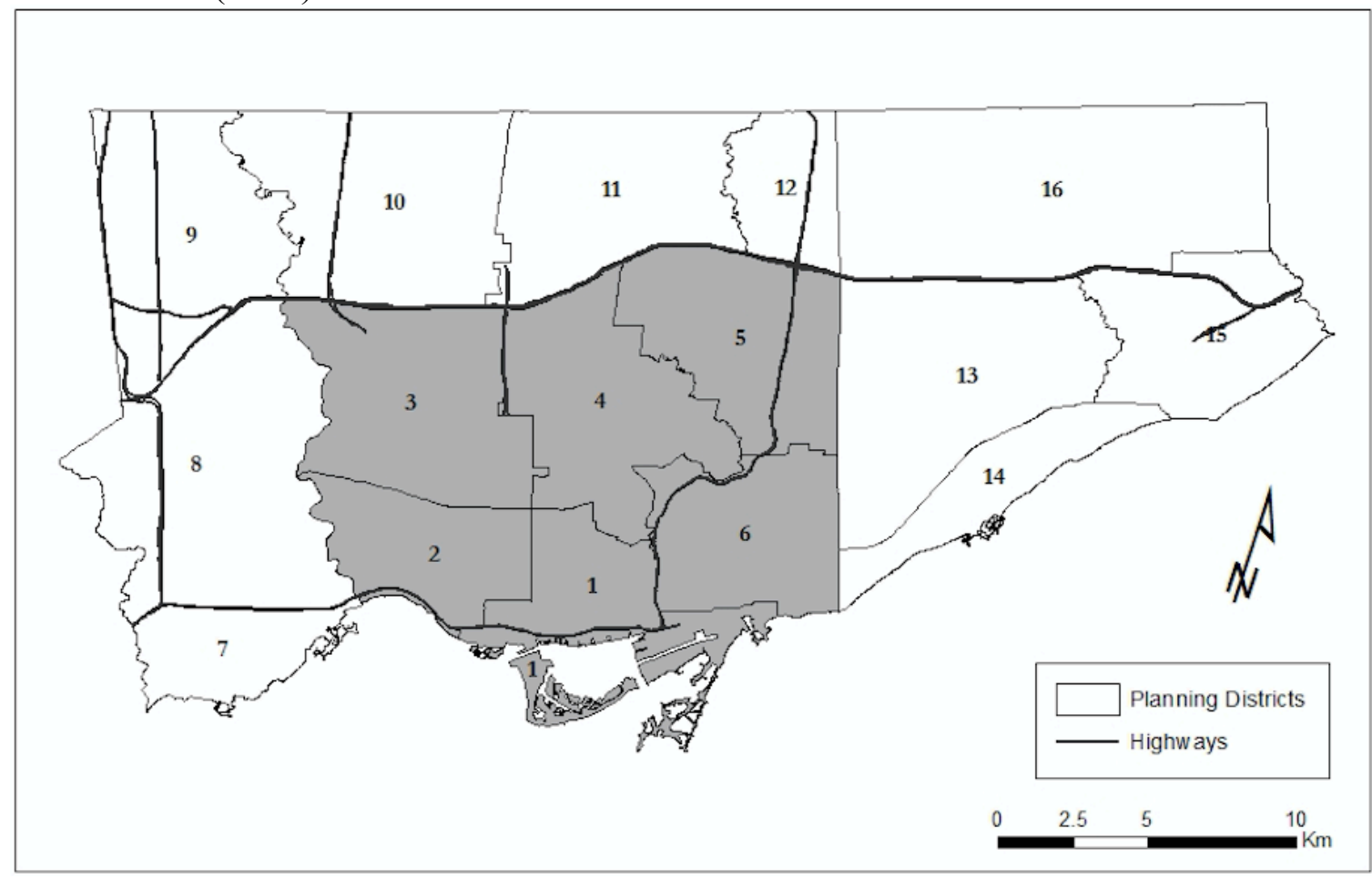

For the purpose of this study, we mainly use data from the latest 2016 version of the TTS, but also complement the analysis with data comparisons from previous TTS cycles. Recognized as the largest travel survey ever undertaken (TTS, 2016), the 2016 TTS uses a mixed sampling approach to maximize representativeness and address its continual decrease in response rates, especially from younger members of the population. In addition to the traditional landline-based survey collection techniques, the 2016 TTS uses a web-based component to assist in the recruitment process, especially for young adults, and prepare for the eventual transition away from a predominantly landline-based survey collection towards a mix of web, smartphones, and in-person data collection (TTS, 2016). All said, the 2016 TTS, which ran from September to December 2016, achieved an overall sampling rate of $5.0 \%$, with the exception of Hamilton (3.0\%). It 
asked participants questions about their household, demographic profile, and the trips made by members of their household on the day prior to being surveyed (respondents must have been eleven years of age or older to participate).

Focusing specifically on mode share, we compare the proportion of trips taken by RS, taxis, public transit (including TTC trips, GO transit trips, and any others local transit trips), car (including both as a driver and as a passenger), active modes of travel (including both walking and cycling trips), and other modes (which includes school bus, motorcycle, and any other mode of travel). The number of trips and corresponding percentages are displayed in Table 1.

Table 1. Mode Share for the six central Planning Districts in the City of Toronto Source: TTS (2016)

\begin{tabular}{lllll}
\hline & Unweighted & \multicolumn{3}{l}{ Weighted } \\
\cline { 2 - 5 } & Trips & Percentage & Trips & Percentage \\
\hline Ride-hailing & 1043 & 0.87 & 23682 & 0.93 \\
Taxi & 1255 & 1.04 & 23181 & 0.91 \\
Public transit & 32556 & 27.01 & 775891 & 30.47 \\
Car & 61128 & 50.71 & 1196002 & 46.97 \\
Active modes & 23804 & 19.75 & 511080 & 20.07 \\
Other & 751 & 0.62 & 16686 & 0.66 \\
Total & 120537 & 100.00 & 2546522 & 100.00 \\
\hline
\end{tabular}

Estimated margin of errors for the survey area are $0.2 \%$ (unweighted), and $0.3 \%$ (weighted) at the $95 \%$ confidence level (TTS, 2016).

Survey weights provided by the TTS, and estimated according to dwelling type, household size, and household age by gender, suggest that RH trips are slightly underreported (TTS, 2016). This prompts the use of weights for our analysis and indicates that RH trips represent $0.93 \%$ of all trips conducted by households living within the central Planning Districts of the City of Toronto. Despite this proportion seeming relatively insignificant at first glance, it is worth noting that RH mode-share increases considerably 
once cross-tabulated with other socioeconomic factors as well as the purpose and timing of trips. For instance, when only considering respondents aged between 20-29, RH accounts for $10 \%$ of all trips occurring between $11 \mathrm{pm}$ and $5 \mathrm{am}$. These factors, among others, will be explored in much greater detail in the following sections, in order to produce a detailed illustration of the usage patterns of this novel mode of transportation in Toronto.

\subsection{Statistical Analysis:}

Descriptive statistics are first used to compare the socioeconomic characteristics of $\mathrm{RH}$ users to that of other mode users. Chi-square tests are also displayed to determine the socioeconomic characteristics that are significantly associated with RH usage. Several tables are then presented to compare the timing and purpose of RH trips to that of other modes of travel. The analysis is further enhanced by comparing the 2016 mode share, to that of previous TTS cycles, in order to determine whether the arrival of RH has impacted the ridership level of other modes of travel.

Because of question-specific non-responses (especially with regards to income) the descriptive analysis was carried out on a reduced sample of 102,104 trips (statistical tests conducted on trip characteristics were performed on a smaller sample size to account for additional non-responses). All analyses were conducted using R 3.3.1 and RStudio. Percentages and Chi-squared tests for all descriptive analyses are weighted, using weights provided by the 2016 TTS. 


\section{Results:}

4.1. Who uses ride-hailing?

Weighted descriptive statistics for the socioeconomic characteristics of our sample population and modal subcategories are presented in Table 2. Chi-square test results and significance indicate the presence of a statistically significant relationship between modal decisions and each of the respondents' socioeconomic characteristics. With regards to age, RH users tend to be younger than average, and to be most often aged between 20 and 39 years old. Despite there being slightly more 30-39 than 20-29 year old RH users, RH trips made by $20-29$ year olds represent $2 \%$ of all trips conducted by individuals in this age group, which is more than double the share of RH trips overall, making this age group the most likely to use RH services. RH appears to be a younger generation phenomenon, as illustrated by the fact that less than $2 \%$ of its users are aged 60 years and over. This is likely due to the prevailing digital divide between younger and older generations, and to only $30 \%$ of elder, aged 71 years old and over, in Canada now owning a smartphone capable of ordering a RH trip (Media in Canada, 2017). RH users are also the most likely to be employed full-time and live in a household earning over $\$ 125,000$. Half of all $\mathrm{RH}$ users are also shown to own a monthly transit pass, which is significantly more than with taxi users (38\%), and may provide support to the hypothesized complementarity of RH with regards to public transit, as to cost-effectively own a monthly transit pass in Toronto, users must ride multiple times per day. In addition, RH users appear to be the most likely to not have a vehicle in their household, which may be partially explained by the fact that we are solely considering households living in central Planning Districts, where car ownership rates are already low to begin with. Despite its potential complementarity to transit, the question of equity still remains 
of utmost importance, as RH trips are often more expensive than transit and unaffordable to many low income households, as exemplified by only $2.6 \%$ of RS's users living in households with incomes less than $\$ 15,000$.

Table 2. Descriptive statistics of socioeconomic characteristics of respondents (weighted) Source: TTS (2016)

\begin{tabular}{|c|c|c|c|c|c|c|c|}
\hline Variables & $\begin{array}{l}\text { Ride- } \\
\text { hailing }\end{array}$ & Taxi & $\begin{array}{l}\text { Public } \\
\text { transit }\end{array}$ & Car & $\begin{array}{l}\text { Active } \\
\text { modes }\end{array}$ & Other & Total \\
\hline Row percentage & 0.98 & 0.90 & 30.41 & 46.46 & 20.66 & 0.59 & 100.00 \\
\hline Number of unweighted Obs. (Trips) & 935 & 1056 & 27584 & 50965 & 20951 & 613 & 102104 \\
\hline \multicolumn{8}{|l|}{ Column \% } \\
\hline \multicolumn{8}{|l|}{ Age: (years) } \\
\hline $10-19$ & 5.72 & 1.59 & 10.78 & 5.43 & 12.77 & 50.18 & 8.80 \\
\hline $20-29$ & 35.17 & 11.46 & 24.42 & 10.38 & 23.31 & 7.31 & 17.55 \\
\hline $30-39$ & 39.27 & 26.70 & 23.64 & 21.00 & 29.55 & 13.68 & 23.76 \\
\hline $40-49$ & 13.05 & 19.72 & 15.33 & 23.03 & 15.43 & 7.84 & 18.90 \\
\hline $50-59$ & 4.73 & 15.75 & 13.03 & 20.41 & 9.88 & 9.03 & 15.73 \\
\hline $60-69$ & 1.79 & 13.37 & 8.12 & 12.02 & 6.01 & 9.56 & 9.49 \\
\hline $70-79$ & 0.27 & 5.92 & 3.50 & 5.63 & 2.37 & 1.12 & 4.23 \\
\hline $80+$ & 0.00 & 5.49 & 1.17 & 2.10 & 0.68 & 1.28 & 1.53 \\
\hline \multicolumn{8}{|l|}{ Income: $(\$)$} \\
\hline$\$ 0$ to $\$ 14,999$ & 2.67 & 4.10 & 6.51 & 2.47 & 6.24 & 4.19 & 4.50 \\
\hline$\$ 15,000$ to $\$ 39,999$ & 8.55 & 12.17 & 17.38 & 9.60 & 12.06 & 19.02 & 12.54 \\
\hline$\$ 40,000$ to $\$ 59,999$ & 10.69 & 9.64 & 16.58 & 12.20 & 13.06 & 13.97 & 13.68 \\
\hline$\$ 60,000$ to $\$ 99,999$ & 23.96 & 18.12 & 24.40 & 22.67 & 25.49 & 30.14 & 23.80 \\
\hline$\$ 100,000$ to $\$ 124,999$ & 11.94 & 15.03 & 11.80 & 13.28 & 12.98 & 8.64 & 12.74 \\
\hline$\$ 125,000$ and above & 42.18 & 40.94 & 23.32 & 39.78 & 30.18 & 24.03 & 32.73 \\
\hline \multicolumn{8}{|l|}{ Cars per household } \\
\hline 0 & 49.15 & 41.39 & 48.81 & 2.40 & 46.27 & 16.21 & 26.47 \\
\hline 1 & 35.83 & 44.62 & 38.82 & 55.10 & 41.46 & 41.80 & 46.97 \\
\hline 2 & 12.98 & 11.05 & 10.53 & 34.47 & 10.77 & 31.46 & 21.85 \\
\hline $3+$ & 2.04 & 2.94 & 1.84 & 8.02 & 1.49 & 10.53 & 4.71 \\
\hline \multicolumn{8}{|l|}{ Student Status } \\
\hline Full-time & 14.46 & 1.86 & 19.41 & 7.37 & 20.94 & 54.32 & 14.13 \\
\hline Part-time & 5.17 & 3.70 & 4.28 & 2.42 & 3.76 & 1.91 & 3.30 \\
\hline Not a Student & 80.37 & 94.44 & 76.31 & 90.21 & 75.30 & 43.77 & 82.57 \\
\hline \multicolumn{8}{|l|}{ Employment Status } \\
\hline Full-time & 73.41 & 68.29 & 59.50 & 63.26 & 58.13 & 24.85 & 60.98 \\
\hline Part-time & 11.28 & 6.74 & 13.70 & 10.27 & 13.07 & 10.22 & 11.87 \\
\hline
\end{tabular}




$\begin{array}{lccccccc}\text { Unemployed } & 15.31 & 24.97 & 26.81 & 26.46 & 28.80 & 64.92 & 27.15 \\ & & & & & & & \\ \text { Female } & 52.06 & 52.73 & 55.08 & 48.13 & 50.47 & 44.77 & 50.79 \\ \text { Drivers license } & 81.10 & 75.67 & 65.32 & 92.48 & 73.00 & 45.11 & 79.66 \\ \text { Monthly transit pass } & 49.41 & 38.26 & 69.73 & 15.66 & 35.78 & 20.50 & 36.83 \\ \text { a } & \end{array}$

\subsection{When do people use ride-hailing?}

As seen in Table 3, trip start time greatly influences the choice of mode. Despite cars remaining the most widely used mode of travel throughout the entire day, several variations can be observed when dividing the day up into separate time periods: Morning (5-10am), Midday (10am-3pm), Afternoon (3-7pm), Evening (7-11pm), and Night (11pm-5am). Corroborating Murphy and Felgon's (2016) findings, RH appears to account for the highest proportion of all trips during the evening and at night, representing $2.3 \%$ and $7.4 \%$ of all trips during these periods, respectively. We were also able to replicate Bialik et al.'s (2018) finding in New York City, and found RH trips to occur most frequently in the evening, representing $31.4 \%$ of all $\mathrm{RH}$ trips during this period. Moreover, in periods where RH represents the largest share of trips, public transit ridership appears to be at its lowest. This modal juxtaposition can either be used to support the claim that $\mathrm{RH}$ is taking riders away from public transit, or instead provide evidence towards its complementarity, as $\mathrm{RH}$ is most often used at times when transit ridership, and service, are already at their lowest level. To better understand the effect that RH has had on public transit, we now turn our attention towards the purpose of trips and determine the extent to which these overlap across modes. 
Table 3. Start time of trips by mode

Source: TTS (2016)

\begin{tabular}{llllllll}
\hline & $\begin{array}{l}\text { Ride- } \\
\text { hailing }\end{array}$ & Taxi & $\begin{array}{l}\text { Public } \\
\text { transit }\end{array}$ & Car & $\begin{array}{l}\text { Active } \\
\text { modes }\end{array}$ & Other & Total \\
\hline Morning (5-10am) & 0.4 & 0.5 & 33.8 & 43.2 & 21.5 & 0.7 & 100.0 \\
Midday (10am-3pm) & 0.5 & 0.8 & 27.6 & 51.3 & 19.2 & 0.5 & 100.0 \\
Afternoon (3-7pm) & 0.7 & 0.6 & 31.5 & 44.2 & 22.3 & 0.6 & 100.0 \\
Evening (7-11pm) & 2.3 & 1.9 & 25.0 & 52.9 & 17.4 & 0.4 & 100.0 \\
Night (11pm-5am) & 7.4 & 5.7 & 24.9 & 44.6 & 16.8 & 0.7 & 100.0 \\
\hline
\end{tabular}

\subsection{Why do people use Ride-hailing?}

When trying to uphold RS's gap filling potential and its complementarity to public transit, authors often point towards the differing trip purposes they serve. Murphy and Felgon (2016) for instance, show that RS, in contrast to public transit, is seldom used for work trips, and instead, is most often used for social and recreational trips. These divergent trip purposes are also discernable in our study, where less than one-fifth of RH trips are undertaken for work purposes, and roughly one-third of public transit trips are taken for this reason (refer to Table 4). The same can be said for school-related trips, which represent $3.7 \%$ of $\mathrm{RH}$ trips, while accounting for $8.1 \%$ of all public transit trips. Nevertheless, returning home remains the primary reason for using each and every mode of travel, and plays approximately the same role for both $\mathrm{RH}$ and public transit, thus supporting the alleged substitution effect maintained by Clewlow and Mishra (2017). Beyond returning home, the Other purpose category appears to be the second most popular reason for choosing to use RS. According to the TTS, this category includes entertainment, personal business, social and recreational trips and accounts for $28.1 \%$ of all RH trips (TTS, 2016). 
Table 4 . The travel mode of trips by purpose (Column wise percentage)

Source: TTS (2016)

\begin{tabular}{llllllll}
\hline & $\begin{array}{l}\text { Ride- } \\
\text { hailing }\end{array}$ & Taxi & $\begin{array}{l}\text { Public } \\
\text { transit }\end{array}$ & Car & $\begin{array}{l}\text { Active } \\
\text { modes }\end{array}$ & Other & $\begin{array}{l}\text { All } \\
\text { Modes }\end{array}$ \\
\hline School & 3.7 & 0.3 & 8.1 & 2.2 & 8.3 & 25.0 & 5.4 \\
Daycare & 0.2 & 0.8 & 0.6 & 1.7 & 2.8 & 0.4 & 1.6 \\
Facilitate passenger & 0.7 & 0.6 & 0.4 & 8.8 & 2.0 & 0.4 & 4.6 \\
Home & 45.6 & 54.6 & 43.9 & 39.8 & 43.3 & 43.5 & 42.0 \\
Market/shop & 3.9 & 2.4 & 5.1 & 9.7 & 6.9 & 9.6 & 7.6 \\
Other & 28.1 & 26.2 & 12.3 & 15.9 & 12.2 & 9.9 & 14.2 \\
Work & 17.7 & 15.1 & 29.7 & 21.9 & 24.4 & 11.2 & 24.6 \\
\hline Total & 100.0 & 100.0 & 100.0 & 100.0 & 100.0 & 100.0 & 100.0 \\
\hline
\end{tabular}

This being said, when considering the actual number of trips per purpose, a different picture emerges. Despite representing $45.6 \%$ of all RH trips, only $1.1 \%$ of all Home purpose trips are actually made by RS. The same may be said for Other purpose trips, which represent $28.1 \%$ of all RH trips, but account for just under $2 \%$ of total Other purpose trips. See Table 5 for more details.

Table 5. The travel mode of trips by purpose (Row wise percentage) Source: TTS (2016)

\begin{tabular}{llllllll}
\hline & $\begin{array}{l}\text { Ride- } \\
\text { hailing }\end{array}$ & Taxi & $\begin{array}{l}\text { Public } \\
\text { transit }\end{array}$ & Car & $\begin{array}{l}\text { Active } \\
\text { modes }\end{array}$ & Other & Total \\
\hline School & 0.7 & 0.0 & 45.9 & 18.7 & 31.9 & 2.7 & 100.0 \\
Daycare & 0.1 & 0.5 & 11.8 & 50.8 & 36.7 & 0.2 & 100.0 \\
Facilitate passenger & 0.2 & 0.1 & 2.5 & 88.2 & 9.0 & 0.0 & 100.0 \\
Home & 1.1 & 1.2 & 31.8 & 44.0 & 21.3 & 0.6 & 100.0 \\
Market/shop & 0.5 & 0.3 & 20.4 & 59.3 & 18.7 & 0.7 & 100.0 \\
Other & 1.9 & 1.7 & 26.3 & 51.9 & 17.8 & 0.4 & 100.0 \\
Work & 0.7 & 0.6 & 36.6 & 41.4 & 20.5 & 0.3 & 100.0 \\
\hline
\end{tabular}

Table 5 clearly demonstrates the small number of $\mathrm{RH}$ trips and its current insignificance within the transportation sector, but does this insignificance remain once cross-referenced with other socioeconomic factors? 
From Table 2 and 3, we determine that individuals most likely to use RH services are aged between 20-29 years old and that RH trips are most likely to occur at night (between $11 \mathrm{pm}-5 \mathrm{am}$ ). When solely considering trips within this market segment, we find the importance of RH to increase considerably, and even come to represent as much as $10 \%$ of all trips. Measuring the same trip purpose breakdown but for this specific age and time period segment, we find $\mathrm{RH}$ to account for $9.5 \%$ of all Home purpose trips and $24.1 \%$ of all Other purpose trips, making it the second most used travel mode for this later category after only Active modes (see Table 6).

Furthermore, while considering the age and time frame of this subsample, and the fact that entertainment, bars, and other alcohol-related activities are included within this Other category, it becomes apparent that the prominence of RH trips in this category may, be to avoid drunk-driving. Despite not being able to verify this specific trip purpose directly, the portion of $\mathrm{RH}$ trips that exhibit bar-use travel patterns remains considerable, and RS's alleged potential to curtail the occurrence of drunk-driving and its ensuing fatalities remains a plausible outcome. Also striking is how little taxis are being used by this subsample; accounting for only $4.6 \%$ of Home trips and $5.2 \%$ of Other purpose trips, taxis are essentially being ignored by this group, and are most likely not achieving the same level of success in reducing drunk-driving.

Table 6. Trip Purpose by Mode, cross-referenced with Age (20-29 years old) and Time (11 pm-5am)

Source: TTS (2016)

\begin{tabular}{llllllll}
\hline & $\begin{array}{l}\text { Ride- } \\
\text { hailing }\end{array}$ & Taxi & $\begin{array}{l}\text { Public } \\
\text { transit }\end{array}$ & Car & $\begin{array}{l}\text { Active } \\
\text { modes }\end{array}$ & Other & Total \\
\hline School & 0.0 & 0.0 & 28.5 & 0.0 & 71.5 & 0.0 & 100.0 \\
Facilitate passenger & 0.0 & 0.0 & 0.0 & 100.0 & 0.0 & 0.0 & 100.0 \\
Home & 9.5 & 4.6 & 30.4 & 31.3 & 22.9 & 1.3 & 100.0 \\
Market/Shop & 0.0 & 0.0 & 37.3 & 36.1 & 26.5 & 0.0 & 100.0
\end{tabular}




\begin{tabular}{llllllll} 
Other & 24.1 & 5.2 & 20.3 & 21.4 & 29.1 & 0.0 & 100.0 \\
Work & 8.3 & 1.9 & 16.0 & 55.4 & 18.4 & 0.0 & 100.0 \\
All modes & 10.0 & 4.3 & 28.2 & 33.5 & 22.9 & 1.1 & 100.0 \\
\hline
\end{tabular}

\subsection{Comparison to previous TTS cycles.}

Due to the small number of RH trips in comparison to overall trips in our survey, it is to be expected that its inclusion as a mode will have no significant effect on mode share proportions at the most aggregated levels, and that when compared to previous TTS cycles, no notable differences will emerge. Indeed, by comparing the 2016 mode share to that of previous cycles, certain temporal trends emerge, such as the rise of public transit and active mode trips, and the slow, yet perceivable, decrease in car trips, but the most notable finding of all is the extent to which these trends have been largely unaffected by the arrival of RS. RH represents $1 \%$ of all trips and cannot in itself, decelerate modal trends, let alone reverse them.

For this reason we conduct our temporal analysis on individuals aged 20-29, traveling at night, for Other purposes. Presented in Table 7 is the weighted percentage of trips made by each mode on the days the survey was collected for each of the past four TTS cycles. It is worth noting that because RH companies made their first appearance in Toronto in 2012, they do not appear as a travel mode in previous TTS cycles and are therefore assumed to account for $0.0 \%$ of all trips during these years. Despite still representing a considerable share of trips, the role of cars appears to have declined over time, falling from $66.4 \%$ to $21.4 \%$ of all trips for this market segment between 2001 and 2016. In an attempt to better understand this decline in car trips, we consider the modes drivers must have turned towards instead. From 2001 to 2016, active modes of travel have increased $22.6 \%$, public transit trips has risen by $7 \%$, while taxis and $\mathrm{RH}$ together, 
have increased by $16 \%$. This last percentage, however, is entirely due to RS, as taxis actually declined by $8.1 \%$ during this period. Taxis, which previously accounted for as much as $35.4 \%$ of all trips conducted by this subsample, are arguably the most affected by RH and now only account for $5.2 \%$ of trip made by them. To address concerns over sampling error, we employed difference in proportion tests and found the 2016 mode share proportion to be significantly different to that of 2006 and 2011. The 2001 mode share proportion was found to be similar to 2016, but became different when combined to 2006 and 2011, to determine whether, together, the three previous cycles had a different mode share proportion to that of 2016 . The perceivable rise in ridership for both public transit and active modes of travel does not appear to have been affected by the arrival of RS; in fact, if anything RH has only served to accelerate these trends in Toronto. This finding is of particular importance, as it addresses the concerns that RH may be taking riders away from public transit and shows that even with individuals most likely to be using RH (20-29 year olds), during times when RH represents the largest share of overall trips (11pm-5am), and for purposes among the most commonly used for RH (Other trip purposes), transit ridership appears to be unaffected by RS. In addition to this, the increase in active mode share between 2011 and 2016 suggests that many young adults are now choosing to forgo their cars, and instead choose to travel by active modes of travel, knowing full well that, were their plans or the weather to change, alternative travel modes, such as RS, are just a phone tap away. Coupled together, these later findings demonstrate that, at least in this narrow demand segment, the fear that $\mathrm{RH}$ would be detrimental to the City's sustainable transport objectives is clearly exaggerated. 
Table 7. Mode share comparison to previous TTS cycles, and cross-referenced with Age (20-29 years old), Time (11pm-5am) and Purpose (Other)

Source: TTS $(2001,2006,2011,2016)$

\begin{tabular}{lllllllc}
\hline Year & $\begin{array}{l}\text { Ride- } \\
\text { hailing }\end{array}$ & Taxi & $\begin{array}{l}\text { Public } \\
\text { transit }\end{array}$ & Car & $\begin{array}{l}\text { Active } \\
\text { modes }\end{array}$ & Other & $\begin{array}{l}\text { Total num. } \\
\text { of Other } \\
\text { purpose trips }\end{array}$ \\
\hline 2001 & 0.0 & 13.3 & 13.3 & 66.4 & 6.5 & 0.5 & 173 \\
2006 & 0.0 & 35.4 & 17.7 & 38.4 & 8.5 & 0.0 & 99 \\
2011 & 0.0 & 22.8 & 16.3 & 44.6 & 16.3 & 0.0 & 39 \\
2016 & 24.1 & 5.2 & 20.3 & 21.4 & 29.1 & 0.0 & 43 \\
\hline
\end{tabular}

a In addition to the aforementioned subsampling criterions, mode share comparisons are strictly conducted on individuals living in household within the central six Planning Districts of the City of Toronto. $\mathrm{b}$

Percentages are weighted, the total number of Other purpose trips is unweighted.

\section{Discussion:}

\subsection{Key findings}

The purpose of this paper was first to compare the socioeconomic and trip characteristics of RH users to that of other mode users, in hopes of uncovering the distinctive traits of RH users, and better understanding its effect on urban transportation systems and cities. Our results confirm that $\mathrm{RH}$ is largely a younger generation phenomenon, with only $2 \%$ of its users being aged 60 years and over, and majority ranging from 20-39 years old and belonging to the Millennials generation. This finding closely aligns itself with that of the Nielsen Company (2012), which finds technology to be the defining attribute of the Millennials generation, and is consistent with the work of McDonald (2015), which finds Millennials to be less likely to own a car - a trait also associated with RH users in our study.

Our results also indicate that a majority of $\mathrm{RH}$ users are wealthy, as $54 \%$ of them live in a household that earns over $\$ 100,000$ per year and only $2.6 \%$ live in households with incomes of less than $\$ 15,000$, as opposed to $45.5 \%$ and $4.5 \%$, respectively, for all modes combined. These findings bring up issues of equity and beg the question as to 
whether RH services are actually available to all? In Toronto, Uber bills itself as being much cheaper than taxis, and to cost as little as $\$ 7.20$ for a $6 \mathrm{~km}$ trip (average length of RH trips). Despite being cheaper than taxis, this trip remains considerably more expensive than the $\$ 3.25$ public transit fares, and is therefore only conceivably used by those who can afford it. City officials and planners who view RH as a complement to public transit should therefore attempt to reduce the disparity in costs between $\mathrm{RH}$ and public transit before contemplating its integration within their public transit networks. The integration of RH within the transit system has occurred in small towns such as Innisfil, in Ontario, Canada, where the City has collaborated with Uber and agreed to subsidize all rides going from pre-determined points of interest within the City (Cane, 2017). Other companies such as Lyft are also looking into partnerships with public transit agencies to offer customized vehicles to passengers with special needs (Hamilton, 2017). Examples like these however, are usually found in small cities, where supplying public transit over a large area without sufficient demand is costly and inefficient.

Another objective of this paper was to determine whether RH had impacted the ridership level of other modes of travel. While our results do show that, for the time being, $\mathrm{RH}$ is clearly too minute and inconsequential to influence the ridership level of other, more substantial modes of travel, such as public transit and cars, we do find its arrival to correspond to a significant decrease in taxi ridership and a rise in active modes of travel in specific market segments. Although not directly proving that RH may be used to avoid drunk-driving, the fact that 20-29 years olds are the most likely to use this mode, that they represent the highest share of mode at night (11pm-5am) and that they often serve Other purposes such as entertainment, bars, and other alcohol-related 
activities does support this potential benefit, and begs the need for additional research in this field. Further this suggest that as more and more individuals familiarize themselves with RH services and start using them on a regular basis, they may eventually affect the level of ridership of other modes of travel as well.

\subsection{Limitations}

While our findings show RH to be more expensive, per trip, than public transit, this is only accurate when RH trips are conducted alone. More and more, RH companies are pushing towards reducing the number of single-occupant $\mathrm{RH}$ trips by introducing services such as split fare features and carpooling options (e.g. UberPool), to facilitate cost sharing and enable passengers traveling in the same general direction to share rides. Together, these services are poised to reduce the cost of $\mathrm{RH}$ trips and place it in range with that of public transit. These efforts seem to be working, as the average occupancy of an Uber ride in 2016 was 2.1 passengers, which largely surpasses taxi's 1.1 passenger average (Rayle et al., 2016). We were unfortunately unable to measure the number of passengers per RH vehicle with our dataset, but resolved instead to comparing the level of Google searches for Uber and UberPool in Ontario during the period of our study, and found Uber to be searched, on average, 70 times more than UberPool. While this does not prove nor disprove the successfulness of RS's carpooling options, it does point towards the novelty of this service, and indicates that it may not yet have caught on to the same extent as regular Uber services in Ontario. A relevant addition to this study would be to include actual ridership data, or, at the very least, to recalculate these Google search queries, to determine whether the gap between Uber and UberPool has diminished over time. 
Another limitation of this study is the lack of information regarding surge pricing. Despite surges occurring during 2016 TTS data collection period, no information was available regarding the level and duration of these surges for the Toronto region. This is concerning as past studies (Greenwood and Wattal, 2015; Brazil and Kirk, 2016) have shown Uber's potential to curtail drunk-driving to subside once surge pricing was in effect. Historical data on the level and timing of surge pricing would considerably increase the reliability of results established in this study.

It is also worth noting that results from the 2016 TTS, as is the case with all new travel surveys, should be used with caution, especially when compared to results from previous survey cycles, as differences in sample frames, survey methods, and data weighting are likely and largely unavoidable (TTS, 2016). For this reason, we have chosen to restrict our analysis to an aggregate level data.

Furthermore, because our dataset relies on a 5\% sampling of households in our survey area, it does not provide as precise information on the cost, volume, and location of ride-hailing trips. This information is much better estimated using total trip counts obtained from ride-hailing companies directly such as in work by Contreras and Paz (2018). Instead, the richness of our dataset lies in the extensive demographic and travel characteristics associated with each user, and our ability to compare our findings to those of previous cycles, when ride-hailing was not yet made available.

\section{Conclusion:}

Our analysis provides a better understanding of the type of users, trips, and repercussions RH services have had on other modes of travel. By assessing the socioeconomic and trip characteristics of RH users and comparing it to that of other mode users, we uncovered 
several distinctive features of RH and established its impact on other modes' ridership. We believe that such insight will be vital, especially as this type of information is often what is most lacking when dealing with ridership data provided by ride-hailing companies directly, in order to identify the appropriate policies needed to accommodate the foreseeable changes imposed by this mode on our cities and urban transportation systems. The growing adoption rates of $\mathrm{RH}$ services will increasingly influence the demand for car ownership and likely determine the viability of other modes of travel in their current form.

\section{Funding:}

Fonds de recherche du Québec - Société et culture (FQRSC) grant.

\section{References:}

Anderson, D. N. (2014). "Not just a taxi"? For-profit ridesharing, driver strategies, and VMT. Transportation; New York, 41(5), 1099-1117.

Barro, J. (2016). New York Taxi Medallion Price Fall Again. The New York Times, www.nytimes .com/2014/12/03/upshot/new-york-taxi-medallion-prices-fall again.html?_r=0. Accessed on August 25, 2018.

Bialik, C., Flowers, A., Fisher-Baum, R., and Mehta, D. (2018). Uber Is Serving New York's Outer Boroughs More Than Taxis Are, FiveThirtyEight. https://fivethirtyeight.com/features/uber-is-serving-new-yorks-outer-boroughsmore-than-taxis-are/. Accessed on May 14, 2018.

Brazil, N., \& Kirk, D. S. (2016). Uber and Metropolitan Traffic Fatalities in the United States. American Journal of Epidemiology, 184(3), 192-198.

Cane, T. (2017). Town of Innisfil Staff Report. Publication DSR-042-17. Town of Innisfil. $11 \mathrm{p}$.

Clewlow, R., \& Mishra, G. (2017). Disruptive Transportation: The Adoption, Utilization, and Impacts of Ride-hailing in the United States, Institute of Transportation Studies, University of California, Davis. 38 p. 
Cohen, A. \& Shaheen, S. (2016). Planning for Shared Mobility. American Planning Association, 583, $111 \mathrm{p}$.

Contreras, D. S. and Paz, A. (2018). The Effects of Ride-hailing Companies on the Taxicab Industry in Las Vegas, Nevada. Transportation Research Part A: Policy and Practice, 115, 63-70.

Cramer, J., \& Krueger, A. B. (2016). Disruptive Change in the Taxi Business: The Case of Uber. American Economic Review, 106(5), 177-182.

Data Management Group. (2017). TTS Introduction. http://dmg.utoronto.ca/ transportation-tomorrow-survey/tts-introduction. Accessed on April 24, 2018.

Greenwood, B., \& Wattal, S. (2015). Show Me the Way to Go Home: An Empirical Investigation of Ride Sharing and Alcohol Related Motor Vehicle Homicide. Fox School of Business Research Paper No. 15-054.

Hall, J. D., Palsson, C., and Price, J. (2017). Is Uber a substitute or complement for public transit?, Working Papers tecipa-585, University of Toronto, Department of Economics. 24 p.

Hall, J. V., \& Krueger, A. B. (2018). An Analysis of the Labor Market for Uber's DriverPartners in the United States. ILR Review, 71(3), 705-732.

Hamilton, A. B. (2017). Mobility on Demand: Operational concept Report. U.S. Department of Transportation. https://rosap.ntl.bts.gov/view/dot/34258. Accessed on August 27, 2018.

Harris, S. and Krueger, A. (2015). A proposal for modernization labor laws for twentyfirst-century workers: The "independent worker." The Hamilton Project, Discussion Paper 2015-10. Washington, DC: Brookings Institution.

Henao, A. (2017). Impacts of Ride-hailing - Lyft and Uber - on Transportation Including VMT, Mode Replacement, Parking, and Travel Behavior. Ph.D. Thesis, University of Colorado at Denver. ISBN 9781369757804.

Kalanick ,T., Hempel, J. (2013). Video and transcript: Uber CEO Travis Kalanick. CNNMoney. http://tech. fortune.cnn.com/2013/07/23/travis-kalanick-uber/. Accessed on May 3, 2018.

Kolanko, D., and Gallinger, Z. (2015). How Much Do You Save by Using Uber? The 10 and 3. http://www.the10and3.com/how-much-do-you-save-by-using-uber/. Accessed on May 14, 2018.

McDonald, N. (2015). Are Millennials Really the "Go-Nowhere" Generation? Journal of the American Planning Association, 81(2), 90-103. 
Media in Canada. (2017). Has New Media Changed Seniors' Love of TV and Print? https://mtm-otm.ca/Download.ashx?file=Files/News/3.\%20MediaInCanada\% 20Seniors\%20And\%20TV.pdf. Accessed on May 18, 2018.

Mothers Against Drunk-driving. (2015). Uber Reveals Ridesharing Services Important Innovation to Reduce Drunk-driving. http://www.madd.org/. Accessed on April 24, 2018.

Murphy, C., and Felgon, S. (2016). Shared Mobility and the Transformation of Public Transit. Report submitted by the Shared-Use Mobility Center (SUMC) for the American Public Transportation Association. 39 p.

Nielsen Company. (2014). Millennials - Breaking the Myths. Nielsen Company, 41.

Rayle, L., Dai, D., Chan, N., Cervero, R., \& Shaheen, S. (2016). Just a better taxi? A survey-based comparison of taxis, transit, and ride-hailing services in San Francisco. Transport Policy, 45, 168-178.

Schaller Consulting. (2017). Empty Seats, Full Streets: Fixing Manhattan's Traffic Problem. http://schallerconsult.com/rideservices/emptyseats.pdf. Accessed on May 18, 2018.

Silver, N., \& Fischer-Baum, R. (2015, August 28). Public Transit Should Be Uber's New Best Friend. FiveThirtyEight. https://fivethirtyeight.com/features/public-transitshould-be-ubers-new-best-friend/. Accessed on June 2, 2018.

Statistics Canada. (2016). Census Profile, 2016 Census, Toronto. http://www12.statcan. gc.ca/census-recensement/2016/dp-pd/index-eng.cfm. Accessed on May 14, 2018.

Toronto (2016a). Transit Services. https://www.toronto.ca/wp-content/uploads/2018/ 04/8de4-Transit2016-TTC-Final-AODA.pdf. Accessed on April 24, 2018.

Toronto. (2016b). A New Vehicle-for-Hire Bylaw to Regulate Toronto's Ground Transportation Industry. $66 \mathrm{p}$.

Transportation Tomorrow Survey (2016). TTS 2016 Data Guide. http://dmg.utoronto.ca/ pdf/tts/2016/2016TTS_DataGuide.pdf. Accessed on April 24, 2018. 